\title{
An Examination of an Evidence-Based Literacy Program in Rural Georgia
}

\author{
Milton Reese ${ }^{1} \quad$ Sunddip Panesar Aguilar* \\ 1.College of Education, Albany State University, Albany, Georgia, USA \\ 2.College of Health Sciences, University of St. Augustine, St. Augustine, Florida, USA
}

\begin{abstract}
A small rural school district in the southwestern part of the United States required teachers to provide highly effective literacy instruction by implementing an evidence-based reading program called Journeys. With consistently low reading achievement, it was unclear whether teachers were implementing Journeys as prescribed. The purpose of this qualitative case study was to explore teacher implementation of the Journeys program for students at an elementary school in the district. The theoretical framework used to guide the study was Clay's emergent literacy theory. The conceptual framework included five strands of the Journeys reading curriculum, which was derived from Clay's theory. A modified formative program evaluation case study was conducted. Nine teachers who had taught reading and two administrators who supervised reading teachers were purposefully selected for semi-structured interviews. Coding and analysis of interview data indicated that more than half of the teachers were not implementing Journeys with fidelity. Themes that emerged from the interviews were; inconsistent understanding of evidence-based literacy instruction, lack of collaborative planning, teacher's use of an alternate phonics-based resource, focus on technology integration, lack of teacher buy-in, and lack of teacher training in implementation of the Journeys program. Based on findings, a 3-day professional development training was developed to provide training in implementing Journeys' underlying evidence-based strategies. In regard to social change, the study findings could assist school leaders in determining guidelines for the implementation of evidence-based reading curricula. The study findings could assist school leaders and teachers in effective implementation of Journeys and providing quality literacy instruction to enhance student learning in the district. Keywords: Journeys, evidence-based reading, fidelity, reading achievement, reading levels
\end{abstract}

DOI: $10.7176 / \mathrm{JEP} / 11-2-09$

Publication date: January $31^{\text {st }} 2020$

\section{Introduction}

For a number of years, educators around the world have grappled with how to foster content area literacy among students (Moran and Senseny, 2016). Literacy involves negotiating the complex relationships among reading and writing (Clay, 1972), which is challenging for many students. Students should be exposed to a variety of strategies to effectively read and respond to texts (Clay, 1972). Research has shown that exposing students to formal literacy instruction in Grades K-3 is critical in developing highly literate students (Piasta \& Wagner, 2010) and that educational achievement is dependent, in turn, on successful reading development (Melby-Lervåg, 2012). Furthermore, according to Moran and Senseny (2016), early literacy instruction should be included during kindergarten to optimize students' social and emotional development.

Although literacy development will look different depending on the instructional systems and curriculum employed within the school (Clay, 1991), experts agree that teachers play a critical role in assisting students to become efficient readers (Cunningham, Perry, Stanovich, \& Stanovich, 2004; Smith, 2009). Similarly, the International Reading Association (2000) suggested that reading teachers contribute to reading development and students' motivation to read. For students to remain engaged, teachers must provide relatable and purposeful literacy activities (Cunningham et al., 2004). This can be challenging because all students learn at a different pace and in different ways, which means that instruction should be centered on the individual child and aligned with the child's pattern of growth, according to Clay (1972).

Clay (1991) supported the notion that students should be emerged in the learning of alphabets, phonological awareness, symbolic representation, and communication skills. Teacher's metacognition and pedagogical knowledge, thus, are key factors to effective literacy instruction (Clay, 1991). Highly effective teachers are experts who are aware of their performance and are able to adjust instruction as needed to develop students' literacy skills (Clay, 1991). Because students must be actively engaged and highly focused to learn, teachers need to emphasize behavior management to ensure students are productive in the classroom (Cunningham et al., 2004).

According to research, some instructional methods for teaching reading are more effective than others. Snow and Matthews (2016) noted that many teachers spend significant amounts of time teaching phonemic awareness, phonics, vocabulary, fluency, and comprehension. The authors further argued that teachers should provide explicit instruction, sensitivity to the needs of the students, consistent feedback, and verbal stimulation (Snow \& Matthews, 2016). Schools that use a well-rounded literacy program, place emphasis on professional learning, and use early reading strategies produce students with high levels of literacy (Snow \& Matthews, 2016). 


\section{Literature Review}

In the comprehensive review, sources were used to review pertinent information from Google Scholar, ERIC, ProQuest, the Georgia Department of Education website, and various educational websites. The search terms used included: early literacy, effective reading instruction, elementary reading programs, individualized reading instruction, teacher efficacy, and primary reading strategies. The keywords were selected based on importance of early literacy skills which resulted in themes for the study.

\subsection{Program Implementation}

Stakeholders in education want to know if the time and money that is invested in schools is worthwhile. The degree of Journeys reading curriculum implementation at Washington Elementary (a pseudonym) is currently unknown. There are two parts of success of a program: (a) is the program as designed being implemented and (b) are the outcomes for student improvement being met (Stake, 1976). According to Stufflebeam (2003), the purpose of program review could be to improve the quality of a program, but it could also suggest the termination of a program. This study aligns with Stake's responsive evaluation in that it focuses on components of the Journeys curriculum and presents the perspectives of the educators (Stake, 2006). The program implementation review could also be used to implement a project, which is the goal of the study (Stake, 2006). "Is the program being implemented as intended?" is a sample question that could be answered through this review.

\subsection{Struggling Reader Characteristics/Interventions}

One key approach for determining causality for engagement with reading materials is discussed by Valiandes (2016), who shows that low reading achievers also risk reduced efficacy over time. The study linked students' motivations to their self-efficacy, reading comprehension, and out-loud literacy skills, with their high-achieving peers showing increases over the course of the school year even with no reported increases or decreases in this group's motivation levels (Valiandes, 2016). Notably, this makes it essential to implement early learning interventions that motivate low-reading performance students to engage with reading content to improve their achievement scores.

In the educational field, the need to provide comprehensive coverage of students' learning needs as covered by the curriculum is a basic requirement, making the efforts that instructors direct towards curriculum development an instrumental element in the subsequent achievement of learner populations (Mahwasane, 2017). As a result, the development of various instruction approaches presents possibilities for improving content comprehension among students depending on the skills that these programs intend to build over each course year. As a literacy improvement model, blended instruction has shown promise in its capacity to influence the efficacy of literacy across diverse student populations positively. A recent study presented the blended model as capable of increasing gains for all grades through to Grade 7, with Grade 2 students showing the highest literacy gains compared to other grades (Prescott, Bundschuh, Kazakoff, \& Macaruso, 2017). Moreover, individual programs such as Lexia Reading Core 2 show gains in non-word reading and subsequently improved scores for at-risk students whose learning difficulties were not a result of deficits in working memory (O'Callaghan, McIvor, McVeigh, \& Rushe 2016). This illustrates the need for instructors to consider implementing these programs for literacy interventions to ensure that they can achieve comparable gains for low-reading at-risk students in their classrooms.

\subsection{Teacher and Student Perception of Early Literacy Skills}

As the primary sources of learning content, teachers provide an invaluable reference for students to develop their understanding of and attitudes towards literacy skill development across the field of education. Fletcher and Nicholas (2016) argued that curriculum subjects require different albeit comparable approaches to content delivery, whereby the materials are developed to match the expected reading ability for each grade. Although O'Callaghan et al. (2016) showed reduced support for literacy programs in low-performing school districts, a comparable analysis in Australia reveals that the socio-cultural profiles of individual students do not negatively influence their perceptions towards learning (Fletcher \& Nicholas, 2016). The research revealed that the analyzed student populations were more dependent on teacher attitudes for determining the views that they had regarding the importance of literacy skills.

The research by Fletcher and Nicholas (2016) is an essential addition to the literature since it provides empirical support for further analysis of teachers' roles in influencing students' perception of reading and comprehension. However, while the literature is less expressive regarding other sociocultural influences on learners' attitudes, McDonald (2017) introduced a more recent view into pedagogy by proving that parents' reading ability does not factor into students' motivation to study. Therefore, even as McDonald (2017) highlighted the possible benefits of including parents as stakeholders in students' learning, the literature reveals that they can reinforce learned content while limited in the influence that their involvement or lack thereof has on students' perceptions of the learning process. The explicit teaching methods that Fletcher and Nolan, and Molla (2018) introduced in their research are highlighted as effective in providing students with the multi-sensory learning model 
that McDonald (2017) implements using iPads for increased engagement. The development of such strategies is dependent on teachers' awareness and timely response to individual learners' needs, which emphasizes the roles of their position as instructors and human resource elements for implementing the curriculum in their individual subjects and grades.

\subsection{Effective Reading Instruction}

Although the effects of learner and instructor perceptions are highlighted as instrumental in determining literacy skills, the differences in instructional approaches also correlate to literacy proficiency reported in these various settings. Analyses of international educational settings have yielded studies such as Huo and Wang's (2017) analysis of learning outcomes for children learning English as a foreign language, noting that the majority of literature has always focused on analyzing English as a native language. The use of phonological awareness instruction is highlighted in the research as essential in determining the underlying skills that influence learners' understandings, which include non-word reading and phonemic awareness (Huo \& Wang, 2017). Additional research by Lipka (2017) validated this model as applicable in teaching approaches for children's literacy programs, with the phonics instruction approach being crucial in enhancing learners' capacity to understand the essentials of English spelling rules. However, Huo and Wang (2017) also noted that there are concerns over the influence that early adoption of this instruction approach can have on learners' conversational skills, with the researchers highlighting that teachers' confidence in their own skills can also influence the attractiveness of the phonological awareness instruction approach.

Aside from differentiated and phonological awareness instruction approaches, it is also vital for pedagogy analyses to include the use of blended approaches for delivering learning content. Schechter, Macaruso, Kazakoff, and Brooke (2015) presented computer-aided instruction as a vital aid for teaching efforts, complementing teachers' efforts by availing pre-controlled materials to the learners through digital content delivery channels. Therefore, to achieve optimal results, there is a need for teacher-led instruction and interventions in the classroom setting, which is essential in ensuring that students can improve their phonological awareness, word identification skills, word fluency, as well as the acquisition of letter sounds (Schechter et al., 2015). Similar results were achieved by Prescott et al., (2017), who found that students reported blended instruction as a fun, engaging, and motivational experience in adherence to the improvements in reading fluency for the analyzed population.

While the instruction approaches above are effective in improving literacy scores, the differences in student achievement across the United States (U.S.) are a persistent concern for the success of measures that the educational sector implements for early literacy. According to Prescott et al. (2017), up to two-thirds of all schoolgoing children in the U.S. failed to achieve the benchmark proficiency levels by the fourth grade, which could also reduce the opportunities available to them in later educational and professional life. However, it is also evident that professionals in the U.S. education sector are aware of the influence that early literacy has on academic achievement. Even with this existing knowledge of teaching strategies and their outcomes for students, Prescott et al. (2017) highlighted that only five of 50 states have achieved the seven indicators that the National Assessment of Educational Progress cites as vital in the development of policies that reduce achievement gaps across student populations. Therefore, it is essential for policymakers to acknowledge and incorporate the findings into their decision-making for education approaches, especially considering the disadvantageous position to which lowerincome populations are relegated due to ineffective coverage of their literacy needs.

\subsection{Early Literacy and Strategies}

School failure is highly possible if children are not on grade level in reading by the end of third grade (Snow \& Matthews, 2016). The study conducted by Snow and Matthews (2016) revealed that pre-kindergarten and Grades 1-2 instruction strategies were a vital determinant of students' future outcomes in both educational and careerrelated environments. One key drawback in Snow and Matthews' (2016) study was that teachers are less likely to implement a curriculum that they have a negative attitude towards. Additionally, the findings also revealed that effective assessment of students' needs is a required deliverable for teachers, allowing for the identification of student cases that require more direct attention to achieve peer-level results (Snow \& Matthews, 2016). Nonetheless, researchers explained, there was distinct support for a multi-stakeholder approach to the development and improvement of language instruction in early childhood reading programs (Huo \& Wang, 2015).

According to Mahwasane (2017), it is vital for children to experience differentiated interactions with learning content to allow them to effectively comprehend the material and understand the ideas expressed in the text. The baseline in this research holds that children who regularly interact with text are also able to learn faster than their compatriots, thereby supporting the idea of a fast-paced learning program that introduces children to varied reading materials at younger ages (Mahwasane, 2017). However, there are concerns as to the efficacy of rushed approaches to implementing this strategy, with Connor et al. (2016) noted that the self-regulatory aspect is vital in this learning process. In fact, the research showed a reduction in students' reading stability over time, which was attributed to the improved efficacy of the literacy instruction content served to these student populations (Connor et al., 2016). 
This creates a premise for targeted rather than blanket approaches to the application of early literacy strategies for younger learners. Additionally, the need for active participation from the learners highlights a need to consider young learners' learning capabilities effectively to avoid negatively influencing their capacity to develop in other areas such as in their cognitive processes.

When discussing the issue of literacy, acknowledging the theoretical foundations of exactly what constitutes the effective delivery of teaching content to the learner is important. According to Tighe, Wagner, and Schatschneider (2015), the ultimate goal of reading activities is for readers to acquire the information, synthesize and integrate text, and actively obtain meaning from their readings to achieve adequate levels of comprehension. Evidently, this is an essential process for third-grade students to undergo when building their literacy skills at this developmental stage, which Easton (2015) found has an influence on the subsequent opportunities available to these children in their later educational and professional lives. Considering that children thereby have the potential to become more economically competitive later in life only if they succeed early in reading, it is necessary to ensure that teachers are aware of strategies that can improve students' experiences and literacy skills (Tighe et al., 2015). This validates concerns regarding the quality of the teaching strategies that language teachers utilize when building the literacy skills of students in the third and fourth grades, necessitating considerations for solutions that can equitably equip all learners with the necessary proficiencies.

Lipka (2017) researched a sample of second-grade students and found that students' linguistic, cognitive, and literacy skills were predictive factors for their fluency, adding that phonological awareness influenced fluency across all analyzed age groups. The implications here are that the possible gains to be made with the introduction of programs targeting fluency should include variations of these facets, making it essential to understand the dynamics of their influence on learner outcomes. The use of alternative teaching methods that deviate from traditional classroom approaches, including measures such as the inclusion of rhythmic content delivery, as well as the use of open class environments encourage interaction (Mahwasane, 2017).

\section{Problem, Research Questions, Sampling, Data Analysis, Findings}

\subsection{Problem Statement}

Due to consistently low reading scores, officials in the U.S. state of Georgia placed Washington Elementary School (pseudonym) on the state's failing schools' list in 2015 (Georgia Department of Education [GADOE], 2015). The reading levels of third-grade students were significantly lower when compared to other school districts with similar demographics. Washington Elementary School is classified as a Focus School, which means that schools are in the lowest $10 \%$ of the state (GADOE, 2015). Due to the lack of academic success, school leaders at Washington Elementary need to increase performance for all students, particularly ones struggling in literacy development. They must put in place progressive interventions to prevent the school from being classified as a Priority School. GADOE identifies Priority Schools as schools that failed to make adequate progress within the three-year time frame of being classified as a Focus School (GADOE, 2015).

Georgia also rank schools by the three-year average of achievement gap scores (GADOE, 2015). GADOE (2015) refers to achievement gaps as a year-to-year measurement of the lowest achieving students in the school. Priority Schools have achievement gap scores that are in the lowest 5\% of the state (GADOE, 2015). Focus Schools such as Washington Elementary School are required to develop a leadership team that meets a minimum of two times per month to develop and implement short-term action plans and monitor implementation of actions and interventions to support the lowest-performing students and those not meeting standards (GADOE, 2015). In Georgia, SchoolDigger, a test database, ranks elementary schools according to the Georgia Milestones Assessment in each content area. In the 2014-2015 and 2015-2016 school years, Washington Elementary School ranked 1,094 and 1,151, respectively, on the list of 1,233 schools (SchoolDigger, 2016).

In 2012, education officials in the State of Georgia applied for and were granted a waiver from the No Child Left Behind Act. The waiver prompted the creation of the College and Career Ready Index score (CCRPI) to replace the previously used Adequate Yearly Progress (AYP) rating, which is part of the No Child Left Behind Law. The CCRPI is a targeted gain score that is used by GADOE to measure student performance and rate schools; schools are assigned to one of three different categories: Priority, Focus, or Reward Schools (GADOE, 2012). The AYP rating included two categories: Meets or Does Not Meet Standards. On a scale from 0-100, Washington Elementary's CCRPI score was 47.1 in 2015 and 47.5 in 2016 (GADOE, 2016). The state of Georgia mean CCRPI score was 76 in 2015 and 71.7 in 2016 (GADOE, 2016). When compared to other Georgia public elementary schools during a three-year period, Washington Elementary's CCRPI score was in the bottom 10\%. Washington Elementary qualified for the Focus School determination due to the lack of improvement in gap scores (GADOE, 2016). The problem at Washington Elementary School is that it was unclear whether teachers are implementing Journeys, an evidence-based reading curriculum, as prescribed.

\subsection{Research Questions}

The purpose of this qualitative case study was to explore teacher implementation of an evidence-based early 
literacy program for students enrolled in Washington Elementary, a rural elementary school. The primary research question for this study was: How do teachers at Washington Elementary implement or not implement Journeys reading curriculum in their classrooms to increase literacy skills of K-3 students? The following research questions guided the qualitative case study:

RQ1. How do teachers implement the Journeys curriculum as designed into their early literacy instructional practices?

RQ2. What challenges do teachers face in implementing the Journeys curriculum with their students at Washington Elementary?

RQ3. What are teacher's perspectives on the text, technology, writing, and reading aspects of the Journeys reading curriculum?

\subsection{Sampling}

The study included K-3 teachers who teach students in a rural elementary school. Case study research is designed to determine meaning, examine processes, and obtain insight of an individual, group, such as teachers, or situation (Creswell, 2016). Implementing an evidence-based reading program may assist in improving reading instruction and student's fluency for elementary students. In this study, teacher's implementation of early literacy instruction through the use of the Journeys reading program was explored. Case studies focus on specific characteristics of the person or program being studied (Creswell, 2016). Comprehensive interviews were conducted in an attempt to determine the fidelity of Journeys implementation by reading teachers at Washington Elementary. The curriculum has been in place for 4 years without significant improvements in students' reading achievement. In addition, there has not been a formal program evaluation conducted within the school.

Purposeful sampling entails researchers intentionally selecting individuals to better understand the central phenomenon (Creswell, 2016). Each of the participants was an educator at Washington Elementary where K-3 students are being served. The selected individuals have worked with the Journeys reading program for at least one full school term and currently teach reading. A detailed process was used to analyze the data in order to describe, compare, and interpret the participant's reactions and responses (Fink, 2016).

Eleven teachers and administrators agreed to participate in the study. Each participant had at least 1 year of experience with Journeys and currently taught reading. An initial email was sent to prospective participants providing a general overview of the study a request to participate in the study. The researcher sent consent forms to each staff member who agreed to participate in the study: The form explained the study in detail and highlighted the risks and benefits of participation. The teacher interview protocol contained 13 open-ended questions and the administrator interview protocol included 11 semi-structured questions. Participant responses were recorded using an audio recorder and transcribed using NVivo qualitative analysis software. Before coding, a data analysis form was created to summarize the main point of the participants. Google Sheets was used to color-code and highlight common themes. Once all surveys were collected, data were recorded into an Excel spreadsheet for analysis.

\subsection{Data Analysis}

RQ1: Incorporation of Journeys curriculum into early literacy instructional practices. Overall, the data illustrated that phonics instruction was highly regarded at Washington Elementary School. Teacher interviews support the continuation of part of Journeys but also other programs such as Saxon Phonics to assist with phonics skill development. Instruction typically occurred during the 120-minute reading block during small group and whole group time. Teachers B, C, G, and $\mathrm{H}$ incorporated various materials and instructional components from the Journeys curriculum, including trade books, flash cards, sound cards, videos and games. They also explained the importance of phonics, spelling, and comprehension when implementing Journeys. Teachers expressed a variety of misconceptions concerning how Journeys strands should be implemented. Teachers A and D stated, "I just teach the concepts the way that I know how to teach them" (personal communication, November 26, 2018). They did not understand the district's expectations for Journeys implementation. Teacher E only used the informal and formal assessment techniques incorporated in Journeys. However, teacher F only implemented the small group component of Journeys. Lastly, Teacher I used the bare minimum of the Journeys program by providing students with informational texts.

Differentiation, flexible grouping, high student engagement, and support for struggling readers were key aspects of the Journeys program that were appreciated by some teachers and administrators. TKES and Journeys checklists were used by administrators to monitor implementation and provide support to teachers. Other teachers tended to use web-based resources, teacher-made items, outdated reading material, and other sources that may not be supported by research.

Administrators were more positive than teachers concerning the Journeys program's potential for increasing student test grades in reading. Most of the teachers felt that overall Journeys benefited students; however, they also believed that there was a need to supplement Journeys with other materials in order to adequately address the Georgia State Standards of Excellence. Teachers who regularly used the technology component of Journeys 
thought this was a valuable addition for teaching reading; however, at least one teacher did not use the technology resources of Journeys at all. The comfort level of teachers in using the technology component may reflect the limited professional development teachers received in implementing Journeys. One teacher supported the Journeys program and implemented the program as designed. However, based on the teacher reports the Journeys curriculum was not consistently incorporated as designed into the early literacy instructional program in Washington Elementary School.

RQ2: Challenges to Journeys curriculum implementation. Administrators cited the district mandate to implement the Journeys curriculum as a challenge to implementation because there were no other options presented. Teacher buy-in was a major challenge as well. Most teachers preferred to use their own resources instead of or in addition to the Journeys materials. Teachers also believed that Journeys was not significantly better than their previous instructional practices. Therefore, some teachers used their own practices and buy-in was not achieved. Administrators believed that clear expectations on implementation and adequate professional development were not made available to teachers and, as a result, full buy-in and participation were not achieved. Collaboration and training were key challenges teacher faced in implementing the Journeys curriculum with their students at Washington Elementary. Six teachers discussed the need for effective collaboration and seven expressed that their concerns about the lack of training.

All of the teachers used the Journeys program to some degree for teaching reading; however, with uneven implementation of the Journeys program as designed, most teachers continued reliance on other texts such as Saxon to supplement reading instruction. The administrators believed that the mandated Journeys program was being used as the basis for instruction in the classroom. The greatest challenge to implementation voiced by teachers was lack of a formal and consistent professional development program.

RQ3: Perspectives on texts, technology, writing and reading. The reading and writing strands of the Journeys curriculum were viewed by some teachers as not well aligned with the Georgia State Standards of Excellence. Teachers made individual decisions concerning how and when to incorporate the Journeys program in their classrooms. Technology proficiency was high among Washington Elementary teachers. Journeys Strand 2, technology integration, was implemented with proficiency. Thematic patterns across research questions included the inconsistent understanding of evidence-based literacy instruction, lack of collaborative planning, continued focus on phonics beyond that in Journeys requiring the use of other texts and materials, technology integration, and lack of teacher buy-in in regard to Journeys. Findings aligned with the conceptual framework of emergent literacy theory where instructional practices and the awareness of how the role of teachers contribute to effective instruction, as summarized in Table 1 (Clay, 1972).

Quality literacy instruction is critical to student success and school personnel must work to remove all barriers. When implementing a new curriculum, teachers and administrators are faced with the difficult task of integrating new content and teaching practices into the reading program. Insufficient and inconsistent professional development for new program implementation leads to low levels of teacher support for the program, continuation of previous programs and inconsistent reading instruction across the school. The planned project, a 3-day professional development training, is designed to provide the training of teachers in the purposes, processes, and strategies needed to effectively and consistently implement the research-based Journeys program.

\section{Conclusion}

The strength of the research was being able to address the problem of the research study. The creation of professional learning sessions supports the need for support in evidence-based instruction. A limitation of the study is teacher buy-in to carry out and participate in the professional learning sessions. High levels of administrative support could be a possible solution to this problem. The research study outlined the personal reflections and journey as a researcher from the beginning of the program until the end. The goals of the study and of the research remain unchanged: to improve teachers' experiences with new curricula through a study that is both relevant and applicable to the needs of students, teachers, and administrators. It is important to note the information that the research will provide to subject school and potentially other schools. Teachers and administrators were provided an implementation guide to reduce barriers that may arise with a new curriculum. Ideally, the strategies outlined in the research will be used to improve literacy instruction and student literacy rates. In addition, teachers will refrain from the use of resources that are not evidence-based or supportive of the Journeys curriculum.

The study could initiate change within the school district by providing a model and strategies for curriculum implementation. Increases on standardized tests and higher literacy rates are hopes of the research. The research study was developed to help solve the problem at Washington Elementary and to improve student's literacy skills. Thus, teachers and administrators can receive training on the current reading curriculum and best practices for implementation. Educators who experience similar issues in implementation could also use the research and the instructional strategies as a framework for professional learning in their school. The study could also be redelivered to other stakeholders who have an invested interest in curriculum implementation and student success. Researchers have examined changes in curriculum and the implementation of new programs for decades. Barriers 
to implementation with fidelity must be addressed by teachers and administrators before desired results can be achieved.

\section{References}

Clay, M. M. (1972). "Reading the patterning of complex behavior." Auckland, New Zealand: Heinemann Educational Books.

Clay, M. M. (1991). “Becoming literate: The construction of inner control.” Portsmouth, NH: Heinemann.

Connor, C. M., Day, S. L., Phillips, B., Sparapani, N., Ingebrand, S. W., McLean, L. \& Kaschak, M. P. (2016). "Reciprocal effects of self-regulation, semantic knowledge, and reading comprehension in early elementary school." Child Development, 87(6), 1813-1824. Retrieved from https://www.ncbi.nlm.nih.gov/pubmed/27264645

Creswell, J. W. (2016). "Educational research: Planning, conducting, and evaluating quantitative and qualitative research" (4th ed.). Boston, MA: Pearson Education, Inc.

Cunningham, A. E., Perry, K. E., Stanovich, K. E., \& Stanovich, P. J. (2004). "Disciplinary knowledge of K-3 teachers and their knowledge calibration in the domain of early literacy." Annals of Dyslexia, 54, 139-172. doi:10.1007/s11881-004-0007-y

Easton, L. B. (2015). "The 5 habits of effective PLCs.” Journal of Staff Development, 36(6), 24-29. Retrieved from https://eric.ed.gov/?id=EJ1085499

Fink, A. (2016). “How to conduct surveys: A step-by-step guide.” (6th ed.). Los Angeles, CA. SAGE.

Fletcher, J., \& Nicholas, K. (2016). "What can we learn from young adolescents' perceptions about the teaching of reading?" Educational Review, 68(4), 481-496. Retrieved from https://www.tandfonline.com/doi/abs/10.1080/00131911.2016.1144558?scroll=top\&needAccess=true\&jour nalCode $=$ cedr20

http://ccrpi.gadoe.org/2015/

Georgia Department of Education. (2015). "Focus schools." Retrieved from https://www.gadoe.org/SchoolImprovement/School-Improvement-Services/Pages/Focus-Schools.aspx

Georgia Department of Education. (2016). "Georgia department of education." Retrieved from www.gadoe.org

Huo, S., \& Wang, S. (2017). "The effectiveness of phonological-based instruction in English as foreign language students at primary school level: A research synthesis." Frontiers, 2(15), 1. Retrieved from https://www.frontiersin.org/articles/10.3389/feduc.2017.00015/full

International Reading Association. (2000). "Excellent reading teachers: A position statement of the international reading association." Journal of Adolescent \& Adult Literacy, 44(2), 193-199. Retrieved from http://www.jstor.org/stable/40013543

Lipka, O. (2017). "Reading fluency from grade 2-6: A longitudinal examination.” Reading and Writing, 1-15. doi:10.1007/s11145-017-9729-1

Mahwasane, N. P. (2017). "The acquisition of reading in children: A concept paper." International Journal of Educational Sciences, 17(1-3), 76-81.

McDonald, K. J. (2017). "Exploring Factors that Influence African American Males' Reading Achievement and Reading Self-Perception (Doctoral dissertation)." Texas A\&M University-Commerce).

Melby-Lervåg, M. M. (2012). "The relative predictive contribution and causal role of phoneme awareness, rhyme awareness and verbal short-term memory in reading skills: A review." Scandinavian Journal of Educational Research, 56(4), 363-380. doi:10.1080/00313831.2011.594611

Moran, C. E., \& Senseny, K. (2016). "An examination of the relationship between a child's developmental age and early literacy learning." Cogent Education, 3(1), 1-22. Retrieved from https://www.cogentoa.com/article/10.1080/2331186X.2016.1169577.pdf

Nolan, A., \& Molla, T. (2018). "Teacher professional learning in early childhood education: Insights from a mentoring program." Early Years: Journal of International Research \& Development, 38(3), 258-270. doi: 10.1080/09575146.2016.1259212

O'Callaghan, P., McIvor, A., McVeigh, C., \& Rushe, T. (2016). "A randomized controlled trial of an earlyintervention, computer-based literacy program to boost phonological skills in 4-to 6-year-old children." British Journal of Educational Psychology, 86(4), 546-558. Retrieved from https://www.ncbi.nlm.nih.gov/pubmed/27473924

Piasta, S. B., and Wagner, R. K. (2010). "Developing early literacy skills: A meta-analysis of alphabet learning and instruction." Reading Research Quarterly, 45, 8-38. doi:10.1598/RRQ.45.1.2

Prescott, J. E., Bundschuh, K., Kazakoff, E. R., \& Macaruso, P. (2017). "Elementary school-wide implementation of a blended learning program for reading intervention." The Journal of Educational Research, 1-10. Retrieved from https://www.tandfonline.com/doi/abs/10.1080/00220671.2017.1302914

Schechter, R., Macaruso, P., Kazakoff, E. R., \& Brooke, E. (2015). "Exploration of a blended learning approach to reading instruction for low SES students in early elementary grades." Computers in the Schools, 32(3-4), 
183-200. Retrieved from https://www.tandfonline.com/doi/abs/10.1080/07380569.2015.1100652

SchoolDigger. (2016). "Georgia elementary school rankings." Retrieved https://www.schooldigger.com/go/GA/schoolrank.aspx

Smith, M. (2009). "Learning how to teach reading: A tale of two beginners and the factors that contributed to their vastly different teaching perspectives." Reading Improvement, 46(4), 247-262.

Snow, C. E., \& Matthews, T. J. (2016). "Reading and language in the early grades." Future of Children, 26(1), 5774. Retrieved from https://www.researchgate.net/publication/309922393_Reading_and_language_in_the_early_grades

Stake, R. E. (1976). "Evaluating educational programmes: The need and the response." Cooperation and Development. Retrieved from https://scholar.google.com/scholar?q=Stake,+R.+E.+(1976).+Evaluating+educational + programmes: + The $+\mathrm{n}$ eed + and + the + response. + Organization + for + Economic + Cooperation + and + Development.\&hl $=$ en\&as_sdt $=0$ \&as vis $=1 \&$ oi $=$ scholart

Stake, R. E. (2006). "Multiple case study analysis.” New York: Guilford Press.

Stufflebeam, D. L. (2003). "The CIPP model for evaluation: An update, a review of the model's development, a checklist to guide implementation." Paper presented at the Annual Conference of the Oregon Program Evaluators Network, Portland, Oregon.

Tighe, E. L., Wagner, R. K., \& Schatschneider, C. (2015). “Applying a multiple group causal indicator modeling framework to the reading comprehension skills of third, seventh, and tenth grade students." Reading and Writing, 28(4), 439-466. doi:10.1007/s11145-014-9532-1

Valiandes, S. (2015). "Evaluating the impact of differentiated instruction on literacy and reading in mixed ability classrooms: Quality and equity dimensions of education effectiveness." Studies in Educational Evaluation, 45, 17-26. Retrieved from https://pure.unic.ac.cy/en/publications/evaluating-the-impact-of-differentiatedinstruction-on-literacy-a

Table 1. Summary of Themes

\begin{tabular}{ll}
\hline Theme & Description \\
\hline 1 & Inconsistent understanding of evidence-based literacy instruction \\
2 & Lack of teacher buy-in \\
3 & Phonics and technology integration are important parts of Journeys \\
4 & Importance of collaborative planning \\
5 & Professional learning and training is needed \\
\hline
\end{tabular}

